\title{
The Effectiveness of the E-Portfolio Using the Students Led Conference Approach for Elementary School Students
}

\author{
Nafik$^{1}$, Prof. Dr. Mustaji, M.Pd. ${ }^{2}$, Dr. Andi Mariono, M.Pd. ${ }^{3}$ \\ ${ }^{1}$ Postgraduate program of Educational Technology, Surabaya State University, Indonesia. \\ ${ }^{2}$ Postgraduate program of Educational Technology, Surabaya State University, Indonesia. \\ ${ }^{3}$ Postgraduate program of Educational Technology, Surabaya State University, Indonesia.
}

\begin{abstract}
E-Portfolios by utilizing information and communication technology provide benefits and convenience in documenting the results of teaching and learning activities with authentic assessments. This study examines the implementation of eportfolio with the student led conference approach to student learning outcomes. This research uses quantitative research methods using a quasi-experimental design. Data were collected from 40 elementary school students using the method independent samples $t$ test. The findings of this study indicate that first, there is a significant increase in student learning outcomes who apply the e-portfolio with the student led conference approach. Second, e-portfolio with the student led conference approach encourages students to be able to find metacognitive abilities in themselves. This research can be a stepping stone for future similar research.
\end{abstract}

Keywords: E-Portfolio, SLC, Student Led Conference, evaluation, learning outcomes.

\section{INTRODUCTION}

Information and Communication Technology (ICT) is currently an integral part of education. It in a variety of teaching context has significantly changed the learning process and outcomes. Starting from the simplest to the most complex, these ICTs (eg Internet, computers, multimedia tools) are used to assist students develop their language skills and meet their communication needs (Barrot, 2016). Therefore the use of electronic portfolios (e-portfolios) as an example of technology applications that will open wide access to quality and fun knowledge, especially in processing authentic assessment (Khairul Basyar, 2017)

Evaluation or assessment is an activity to measure learning outcomes that aims to build thoughts and scientific attitudes of students. Through evaluation activities, students obtain data through classification, processing, and searching for connectivity. The lesson plan is designed by the teacher, prioritized in coaching students to carry out various activities such as: analyzing data, categorizing, categorizing, summarizing, and predicting from discussions or practicum activities. Electronic portfolios are used to evaluate student learning during project-based learning. (Budiarti et al., 2018)

Portfolios are used in many disciplines and although there are many definitions in the literature, portfolios can generally be described as, "a compilation of goals and reflections of work, one's efforts, and progress". In addition, there are various types of portfolios including assessment, work, learning and teaching portfolios, the format of which ultimately depends on the purpose of their development. (Bhattacharya \& Hartnett, nd)

The level of accuracy of conventional portfolio data cannot be updated according to the development of information, because if it is in paper format, the data becomes more static. As for the principles of document practicality in conventional portfolios, it will also experience problems, because the demand for portfolios will result in large piles of paper, this is certainly impractical. resulting in large piles of paper, which is of course impractical. (Ibrahim \& Wargahadibrata, 2016)

Therefore, based on technological developments hence the portfolio format currently developing into an electronic portfolio (e-portfolio). Some opinions regarding the meaning of e-portfolio are as follows. e-portfolio is the use of computer technology to collect and store portfolios in various formats, for example audio, photos, video, or text. E-portfolios are filled by linking each work with easy access and modification to show what students have learned. (Chantanarungpak, 2015) In another definition, e-portfolios are "a collection of digital artifacts including demonstrations, resources, and achievements that represent individuals, groups, or institutions. (Yastibas \& Yastibas, 2015)

E-portfolios generally aim to monitor the development of student competencies (for example, knowledge, skills and attitudes in planning and collaboration). It also aims to stimulate self-assessment and reflection, which are prerequisites for being a lifelong learner. whereas for students, 
the e-portfolio can serve as (1) reflective learner logs, demonstrating progress through the curriculum and (2) a warehouse of evidence about learning outcomes during one semester. (Van der Schaaf et al., 2017)

Several e-portfolio research concepts have been used in education in previous years. (Such as Madhumita Bhattacharya and Maggie Hartnett 2007; CHEUNG, Ron Chi-Wai KWOK 2012; Huri Baturay and Aysegül Daloglu 2014; KatrienStruyven YvesBlieck, and Ve' roniqueDeRoeck 2014; Arfilia Wijayanti and Moh. Aniq Khairul Basyar 2015; Kanokphon Chantanarungpak 2015; Ahmet Erdost Yastibas and Gülsah Cinar Yastibas 2015; Tal Soffer, Tali Kahan and Eynat Livne 2016; Jessie S. Barrot 2016; M Lukitasari, J Handhika and W Murtafiah 2017; Kalthoum Rezgui, H'edia Mhiri and Khaled Gh'edira 2017; Meltem Terence Chun-Ho Olga Smolyaninova and Ekaterina Bezyzvestnykh 2019;

The effectiveness of e-portfolios in authentic assessments is still a hot topic of conversation today. Although previous research has shown that e-portfolios are effective in developing student independence and improving student learning outcomes at junior high school to tertiary levels, however, further research is needed to integrate technology and delivery of student learning outcomes in the form of e-portfolios for elementary school students. .

In order for the delivery of student e-portfolios to be maximized, a student led conference approach is needed in delivering e-portfolios. So that e-portfolio, not only as a storage for student learning outcomes but also to detect the students ability in optimizing the metacognitive sense. In many cases, teachers and parents discuss student progress without having students present, and if students are present, students only play a very small role in the process of delivering learning outcomes. Introducing student led conferencing can be an important step towards incorporating metacognitive skills, autonomy, and feedback in the curriculum. In the student led conference, students take a central role in it. As an active participant in preparation and in the conference itself besides, for preparation and participation in the conference a certain amount of autonomy is required. Furthermore, in the preparation process, students must request for, and handle, feedback and use metacognitive skills, such as monitoring and evaluating their own progress. (Eem \& Haelermans, nd) In this contribution, the delivery of e-portfolios with the student led conference approach is presented as form of delivery.

\section{MATERIALS AND METHODS}

This research is a quantitative research with experimental methods. According to Sugiyono (2019), the experimental method is a quantitative research method used to determine the effect of the independent variable (treatment) on the dependent variable (result) under controlled conditions. The research concept used is a quasi-experimental. Where the quasiexperimental concept has a control group, but it cannot play a full role in controlling external variables that affect the application of research "(Sugiyono, 2019). The form of research design from Quasi Experimental used by researchers is a nonequivalent control group design with the following paradigm:

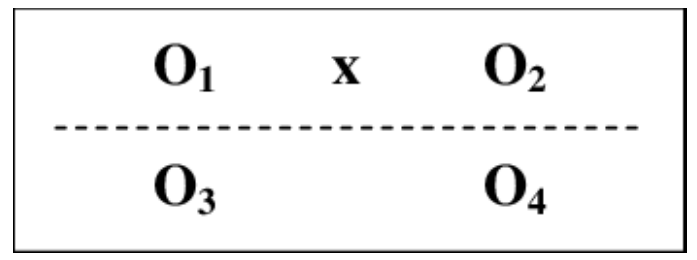

Figure 1. Quasi Experimental Concept (Sugiyono 2019)

Notes:

$\mathrm{O} 1$ and $\mathrm{O} 3=$ initial state of the experimental class and control

$\mathrm{X}=$ treatment given e-portfolio with the student led conference approach

$\mathrm{O} 2$ = learning outcomes of the experimental class after receiving treatment

$\mathrm{O} 4$ = learning outcomes of the control class that were not treated

The population in this study were 40 elementary school students in Class V, consisting of 20 students in the experimental class and 20 students in the control class. Determination of the population in this study was based on several factors, namely: classroom teachers in class VA and B had the same qualifications, namely having the last education of S1 elementary education; students in both classes have the same initial ability, as evidenced by the results of the final semiodd score in the report card are not much different. Thus, it is expected that students' initial abilities are in the same condition.

In this study, the sample was taken using the proportionate stratified random sampling technique,random sampling which is atechnique by paying attention to strata proportionally (Sugiyono, 2019). Sampling is based on thetable Krecjie with an error rate of $5 \%$. From a population of 40 students, a sample of 40 students was obtained (Sugiyono, 2019) consisting of 20 from the experimental class and 20 from the control class.

The research instrument used for data collection in this study was a list of questions in the form of multiple choices with a total of 20 questions with 4 alternative answers in writing. The reason for choosing the multiple choice interview form is because the questions tested can cover most of the required data, the assessment is objective, and the answers can be corrected easily and quickly (Sudjana, 2012). The questions are made according to the competencies that must be achieved by students in terms of 4 core components, namely the competence of spiritual attitudes, social attitudes, psychomotor and cognitive which are described in the question grid. The questions were tried out first to determine validity and reliability. Another instrument that supports this research is the 
google site application. The google site application is used as a guideline for filling out e-portfolios, so that the portfolio content is in accordance with the standards applied in schools.

To test the validity of the questions using the Pearson correlation. The question is said to be valid if the value of $r$ pearson correlation ( $\mathrm{r}$ count) $\geq$ rtable for two-sided testing at the 5\% significance level. Meanwhile, for reliability testing using Cronbach's Alpha by comparing between rcount and rtable. If rcount> rtable, then the item is said to be reliable.

The prerequisite analysis test includes normality and homogeneity tests. The normality test is carried out to determine whether the sample is normally distributed or not. The data normality test in this study used thetest Lilliefors on the column Kolmogorov-Smirnov. Based on opinion Priyatno (2012) data normality test uses thetest states that the Lilliefors on the column Kolmogorov-Smirnov with the criteria that if the significance is greater than 0.05, then the data is declared normal. The calculation uses the SPSS program.

The purpose of the homogeneity test is used so that thetest formula t to be used can be known. This homogeneity test uses the Levene's test. If the data seen is homogeneous, then the Equal Variances Assumed is used for the t test. If the variances are different, then Equal Variances Not Assumed will be used. If the data group is in a normal distribution, the homogeneity test can be carried out. If the calculation with an error rate of $5 \%$, the homogeneity value can be shown. Data is declared homogeneous if the Significance value is greater than 0.05 .

The final analysis is an analysis used to conclude the research results. The first hypothesis testing is about differences. Analysis of learning outcomes using parametric statistics applying the formula for independent samples $t$ test. This technique is used to test descriptive hypotheses when the data are intervals or ratios (Sugiono, 2015). In this t test, there are several provisions that are used as guidelines, namely if -ttable $\leq$ tcount $\leq$ ttable or a significance value $>0.05$, then $\mathrm{H} 0$ is accepted, and if -tcount <-ttable and tcount > ttable or significance value $\leq 0.05$, then H0 is rejected (Priyatno, 2012).

Meanwhile, the statistical analysis for the effectiveness test (hypothesis 2) used the right side test. To perform the righthand test, you must first find thet valuecalculated, then compare it with the tvaluetable. In testing this second hypothesis using theformula one sample t test. From the test using thetest, $\mathrm{t}$ it will be known the difference in the average sample value in the experimental class compared to the average sample value in the control class. By making the decision if ttable $\leq$ tcount $\leq$ ttable, then $\mathrm{H} 0$ is accepted, meaning that the learning outcomes of students who use e-portfolios with the student led conference approach in the experimental class are no better than the control class. If -tarithmetic > ttable> tarithmetic, then $\mathrm{H} 0$ is rejected, meaning that the experimental class students' learning outcomes are better than the control class.

Researchers have formulated 2 hypotheses. The first hypothesis test is about differences in learning outcomes and awareness of metacognitive abilities of fifth grade elementary school students between those who implement e-portfolios with the student led conference approach. and those who apply eportfolios without the student led conference approach. The second hypothesis test is about the effectiveness of student learning outcomes and the awareness of the experimental class students' metacognitive abilities whether it is better or not than the control class. If the results of the hypothesis test with the independent samples $t$ test prove that there are differences in learning outcomes and awareness of metacognitive abilities in the two groups, then hypothesis testing is carried out to determine whether the e-portfolio is effective or not with the student led conference approach. towards increasing learning outcomes and awareness of metacognitive abilities.

\section{RESULTS AND DISCUSSION}

The average results of the final test scores of students in the two classes showed that there were differences in learning outcomes and awareness of students' metacognitive abilities between those using e-portfolio and the student led conference approach. and those who use e-portfolios without the student led conference approach. This is evidenced by the results of the average report card score in the experimental class of 81.36 , while the control class is only 73.33 .

From the data on the value of student learning outcomes, the prerequisite test of data analysis is carried out which aims to determine the formula used to test the hypothesis. The first analysis prerequisite test, namely the normality test. The data normality test used Lilliefors in the SPSS version 20 program and obtained data on the significance value in thecolumn Kolmogorov-Smirnov of 0.170 in the experimental class and 0.148 in the control class. This means that the significance index in the two classes is $>0.05$ and the data is normally distributed. The next analysis prerequisite test was the homogeneity test. The homogeneity test was carried out using independent samples $t$ test by looking at the significance index in thecolumn equal variances assumed. If the significance value is $\geq 0.05$, the data variance is declared homogeneous. Because the results of the data homogeneity test have a significance value of 0.867 or $>0.05$, the value data is declared homogeneous.

The results of the calculation of statistical analysis using the independent samples $t$ test on SPSS version 20, obtained the results of tcount $>$ ttable $(3.952>2.080)$ and a significance of $0.015<0.05$, so that Ho is rejected. So, it can be concluded that there is a significant difference in the learning outcomes of grade $\mathrm{V}$ students between those using e-portfolios with the student led conference approach and those using e-portfolios without the student led conference approach.

To test whether the e-portfolio with the student led conference approach is effective in improving student learning outcomes, researchers use empirical and statistical analysis. According to 
Sugiyono (2019), the final empirical analysis uses the formula:

$$
(\mathrm{O} 2-\mathrm{O} 1)-(\mathrm{O} 4-\mathrm{O} 3)
$$

Notes:

$\mathrm{O} 1=$ the average value of the initial test results of the experimental class

$\mathrm{O} 2=$ the average result value final test experimental class

$\mathrm{O} 3=$ the average value of the initial test results of the control class

$\mathrm{O} 4=$ the average value of the final test results of the control class

Based on the results of the calculation of the effectiveness of eportfolios using the student led conference approach empirically, obtained positive results, namely [(81,36-60) $(73,33-58,61)]=6.64$. That is, empirically the e-portfolio uses the student led conference approach effective to improve learning outcomes and awareness of students' metacognitive abilities.

Testing the effectiveness hypothesis was also carried out by statistical analysis, by using the one sample $t$ test. Based on the results of one sample t test, values obtained t count is 3.952 and $\mathrm{t}$ table is 2.080. According to the decision making criteria, if $\mathrm{t}$ table $\leq \mathrm{t}$ count $\leq \mathrm{t}$ table, Ho is accepted, meaning that the experimental class student learning outcomes are not better than the control class. If $\mathrm{t}$ count $>\mathrm{t}$ table, Ho is rejected, meaning that the experimental class learning outcomes are better than the control class. Based on the decision making criteria, because the value of $t$ count $>t$ table $(3.952>2.080)$, it was concluded that the student learning outcomes in the experimental class were better than the control class.

Based on the results of a series of tests, it can be concluded that the learning outcomes and awareness of students' metacognitive abilities in the experimental class are better than those in the control class. That is, the success of the learning process using e-portfolio with the student led conference approach more effective than e-portfolios without the student led conference approach.

E-portfolios with the student led conference approach certainly have advantages and disadvantages, therefore teachers need to have good technology literacy skills and good classroom mastery to implement e-portfolios with the student led conference approach. Before carrying out e-portfolios with the student led conference approach, very careful preparation is needed. For example, the teacher must list the concept of eportfolio contents on the google site as an e-portfolio container for students. So, students only need to fill in based on the list that must be filled. Before the implementation of student led conference activities begins, a simulation is carried out between students led by the teacher. In addition, because in this case students are classified as a beginner stage, before the research is carried out students need to be accustomed to using the google site so that during the implementation of the research students can focus more on the process of delivering eportfolios, not on how to make e-portfolios. Thus, activities to deliver student learning outcomes become more conducive because students have already understood their assignments.

\section{CONCLUSION}

Based on the results and discussion of experimental research entitled "E-portfolio effectiveness using the Students Led Conference approach for elementary school students", it can be concluded that the research is: (1) The results of the study indicate that there are differences in learning outcomes and awareness of the metacognitive abilities of elementary fifth grade students between those using e-portfolio with the student led conference approach and those who apply e-portfolios without the student led conference approach. This is evidenced by the data calculated using the formula independent samples $t$ test through the SPSS program which shows that the e-portfolio is using the student led conference approach significantly influence learning outcomes and awareness of students' metacognitive abilities.

The effect of e-portfolio using the student led conference approach on learning outcomes characterized by the value of $t$ count > t table $(2.557>2.024)$ and a significance of $0.015<$ 0.05 . (2) e-portfolio using a student led conference approach is more effective to improve learning outcomes and awareness of the metacognitive abilities of elementary fifth grade students than e-portfolios without the student led conference approach. The effectiveness of e-portfolios using the student led conference approach on the improvement of learning outcomes and awareness of students' metacognitive abilities as evidenced by the mean score in the experimental class is better than in the control class. As explained above that in the experimental class, the average value of student learning outcomes was 81.36, while in the control class it was only 73.33.

\section{ACKNOWLEDGEMENT}

The authors greatly acknowledge the support from Surabaya State University (UNESA) Surabaya Indonesia for providing the necessary resources to carry out this research work. The authors are also grateful to the anonymous reviewers and journal editorial board for their many insightful comments, which have significantly improved this article.

\section{REFERENCES}

[1] Barrot, JS (2016). Using Facebook-based e-portfolio in ESL writing classrooms: impact and challenges. Language, Culture and Curriculum, 29(3), 286-301. https://doi.org/10.1080/07908318.2016.1143481

[2] Bhattacharya, M., \& Hartnett, M. (nd). E-portfolio Assessment in Higher Education. 
[3] Budiarti, IS, Suparmi, A., Skills, C., Saenab, S., Yunus, SR, Skills, IE, Sulistiyo, E., \& Kustono, D. (2018). Higher order thinking skills: using e-portfolio in projectbased learning Higher order thinking skills: using eportfolio in project-based learning.

[4] Chantanarungpak, K. (2015). Using E-Portfolio on Social Media. Procedia - Social and Behavioral Sciences, 186, 1275-1281. https://doi.org/10.1016/j.sbspro.2015.04.063

[5] Eem, M. Van Der, \& Haelermans, C. (nd). The effect of student-led conferences on academic achievement An experiment in Dutch secondary education.

[6] Ibrahim, N., \& Wargahadibrata, RAH (2016). Mapping of E-Portfolio Platform Functions for Lectures in the Department of Curriculum and Educational Technology, Faculty of Education, State University of Jakarta. JTP Journal of Educational Technology, 18(3), 202-214. https://doi.org/10.21009/jtp1803.5

[7] Khairul Basyar, AWMA (2017). Development of an Integrated Thematic-E-portfolio based on a Web Blog to Instill Critical and Creative Characters through Science Learning. Phenomenon: Journal of Mathematics and Natural Sciences Education. https://doi.org/10.21580/phen.2017.7.1.1499

[8] van der Schaaf, M., Donkers, J., Slof, B., Moonen-van Loon, J., van Tartwijk, J., Driessen, E., Badii, A., Serban, O., \& Ten Cate, O. (2017). Improving workplace-based assessment and feedback by an E-portfolio enhanced with learning analytics. Educational Technology Research and Development, 65(2), 359-380. https://doi.org/10.1007/s11423-016-9496-8

[9] Yastibas, AE, \& Yastibas, GC (2015). The Use of Eportfolio-based Assessment to Develop Students' Selfregulated Learning in English Language Teaching. Procedia - Social and Behavioral Sciences, 176, 3-13. https://doi.org/10.1016/j.sbspro.2015.01.437Sugiyono. 2019. Quantitative Research Methods. Bandung: Alfabeta.

[10] Sugiono, Susanto Agus 2015. Easy Ways to Learn SPSS \& LISREL. Bandung: Alfabeta

[11] Priyatno, Duwi. 2012. Quick Way to Learn Data Analysis with SPSS. Yogyakarta: Publisher Andi 